\title{
Development Alternatives in Rural and Unfavourable Areas in the Coastal Area of Ishem-Porto Romano for a Sustainable Development
}

\author{
M .Sc. Shkëlqim Sirika \\ University of Tirana-Albania, (PhD Candidate) Departament of Geography \\ shkelqim.sirika@yahoo.com
}

\section{Doi:10.5901/ajis.2013.v2n9p679}

\begin{abstract}
Even though it seems that transition in Albania is over, there still remain some unfinished issues, in front of which is the thought and development of rural and unfavourable areas. In relation to policies for a sustainable development, it is necessary to start new development approaches for the rural areas and especially the unfavourable ones, which can offer more effective solutions having quicker balancing and integrating effects. Although it doesn't have a considerable size with only 17700 ha, the coastal area of Ishem-Porto Romano consists of some unfavourable areas such as the Porto Romano area and some hilly territories having physical and social-economical conditions which provide a relatively low level of income as a consequence of non-productive land, lack of infrastructure, supporting facilities where therefore the private sector is not interested enough to invest in the current conditions. The challenges confronting these areas require integrated policies for a consistent and balanced social-economical development, based on the experience of the approaches adopted in the developed countries, relying on the modern concept of territorial development. Our research consists of an analysis of the new social-economical developments in this area and the approach towards new development alternatives, orientated by policies for a balanced and consistent development
\end{abstract}

Keywords: Rural Areas, Unfavourable Areas, Sustainable Development

\section{Introduction}

The Ishem-Porto Romano coastal area seen from the viewpoint of a formal region, comprises an area with rural background which although it has a small surface of about $170 \mathrm{~km}^{2}$, it consists of unfavorable areas as well. There are areas which include territories near the coast and hilly territories, having physical and social-economical conditions which provide a relatively low level of income as a consequence of non-productive land, lack of infrastructure, supporting facilities where therefore the private sector is not interested enough to invest in the current conditions. The area we are studying inherited a great economic blackwardness, a result of agro-ecological combination, isolation level, restricted land surface, land gradient and quality, infrastructure restrictions, lack of principal assets and facilities,.etc.

The main activity of this area, even though it is a coastal area, was the agriculture sector. Collectivism of agriculture in the socialist period and fragmentation in small farms nowadays prohibits the increase of agriculture productivity. We can also mention the low level of technology (including irrigation system, mechanization, etc), access in the market, lack of credit and rural financial service, poor quality and high prices of inputs, low level of cooperation etc. Recently this area is experiencing development models based on the success of "tourism industry" combined with models of "local development" such as the road which waves the local potentials in the most sustainable way , and up to the model of "Energy Park" and "Biopark".

The development of rural infrastructure, health and education facilities, economical restructuring comprise an important priority of developing policies of the recent years. Human and natural potentials offered by this area are aimed at being used efficiently and in a sustainable way.

Potentials such as human assets, traditional agro-food, tourism, forests, fishing, water resources, medicinal herbs, etc, comprise evidence of the acceleration of development rate and affect the social and economic life of the local community.

Our research consists of an analysis of the new social-economical developments in this area and the approach towards new development alternatives, orientated by policies for a balanced and sustainable development and integration from a rural area having unfavourable territories into a developed area.In order to conduct this research, we are referred and based on the contemporary literature about the concept of sustainable development, the observation of draft-projects 
of the study area, field observations and national strategies about the sustainable development. There have also been discussions with inhabitants of this area, stakeholders, members of local and central goverment.

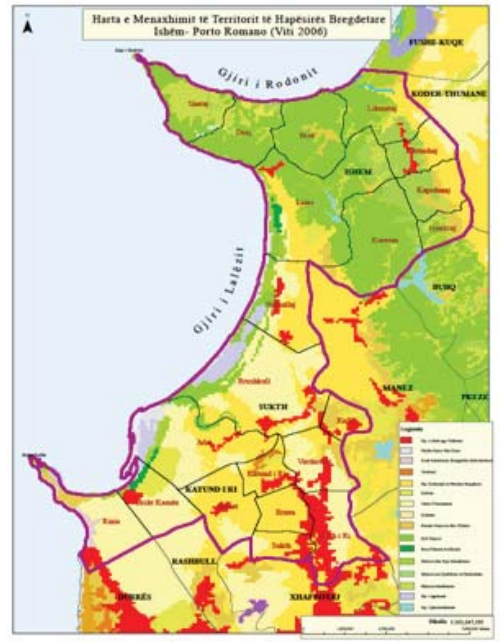

Fig.1. Map of territorial management

\section{General physical-geographical profile of the coastal area of Ishem-Porto Romano}

The coastal area of Ishem-Porto Romano seen as a formal region is situated in the center of the Coastal Lowland of the Albanian Republic, extending from the estuary of the Ishem river in the North to the water-collecting canal of Porto Romano in the South. The estuary in the Adriatic sea, being close to the Durresi Port and Rrinas airport and near the Durres-Kukes road allows this region to have a favourable economic and strategic position. Based on the administrative aspect it includes the communes of Ishem and Katund i Ri.

It has mainly a field relief with some hilly alternations. The hilly relief is in the North in Rodony hills and Bisht Palla in south west and fields lie along the whole coast of Lalzi Bay with a gradient which decreases towards the sea, where you can see depressions up to $1.5 \mathrm{~m}$. The height of the area varies up to $270 \mathrm{~m}$ based on the sea level. The major part of the land is agricultural land, while the primeval hydrophil_orest is almost dispersed, and only some small parts of it are still present along the coast in the north of the estuary of Erzen river. In this area there are natural unfavorable territories as well in the field relief ( Porto Romano) and the hilly one ( Rodon). As unfavorable territories we can define: hilly realms where the gradient, lack of vegetation and erosion phenomena affect the reduction of the production season and the use of mechanization in agriculture, bog realms in depressive areas where there are often floods, salty surfaces and general unfavorable realms characterised by land of poor quality, low productivity or non-productive ones, low density of the population and areas having inherited chemical pollution as well. The study area has been subject to reclamation and deforestation during the past 50 years. The actual marshy parts are reminiscense of the previous moors.

\section{New planning and orientations of economic development, approaches towards sustainable development}

The study area as we highlighted above is included in a new social-economical development process where policies, plans and projects towards the social-economical sustainable development and reduction of differences of intersurface development and between different regions of the country are expected. In this context it is aimed at introducing new development approaches for this area, having the target of a more effective, more balancing and integrating solution of different social-economic factors, including the demographic ones, employment, welfare and the stimulation of a new role for the government.

The new economic development of the area is enabled not only by the natural and human potentials that it offers, but by the approach to the use of new technologies and the new role of capital assets and human resources. These 
technologies are attempted to be adopted through developing projects in unfavorable territories such as the Porto Romano bay and the estuary of Erzen river.

Ambitious projects such as: Industrial Energetic Area of Porto Romano, Biopark (Katund i Ri) and " Lalzi Bay Resort" and the construction of some touristic villages in Lalzi Bay aim for the study area a focus on strategic investments (we can mention the energetic one) and a reduction of non-productive sectors (agriculture);

In this aspect the new economic developments will be oriented towards the efficient use of local resources and the increase of competition ability of this rural region. Through strengthening the local economic capacities, improvement of business and investments climate, increase of productivity, competition in the region and beyond, these developments will improve the facilities and social conditions. This development process intends not only reaching the maximum of efficiency of resources and potentials usage of the study area but minimizing the negative effects and factors about the development.

Some leading main principles of the new economic orientation of the local development of the coastal area IshemPorto Romano should be ${ }^{1}$ :

1. The development projects should base on the local economic and social conditions, building on the competitive advantages and territorial potentials offered by this area.

2. It should have an integrated approach including all the range of sectors and issues affecting the community (social, economic, environmental, spatial,etc.)

3. Focused on the promotion of a favourable environment for the development of local economy, absorption of investments.

4. Include balanced interventions between priorities and developing sectorial and infrastructural activities and those of social issues and increase of capacities and human resources, like necessary components for a sustainable development.

\section{New projects and approaches of the economic development of the area}

\subsection{Energetic and Industrial Area of Porto- Romano}

Actually a part of the investments in relation to the development strategic plans of rural and unfavorable areas in Albania, for the study area are concentrated in the area of Durresi onetime moor (the area of Porto Romano bay), which is not suitable for construction and inhabitation. Among the projects which are being implemented in relation to this development we can mention the "Energetic and Industrial Area of Porto Romano" Campus.

This area includes unfavorable territories from the natural and economical part, such as non productive agriculture land polluted by the ex Chemical Factory in Durres and affected by the sea erosion. Based on the administrative side it is part of the Katund i Ri commune and the selected area consists of a surface of 1367, where 810 ha are for the Energetic Park. Like unfavorable territories it includes 1166 ha non-productive agricultural land, 45 ha forest area, 114 ha regional land and 42 ha building plot and in general the area is characterized of marshy land of very poor quality ${ }^{2}$.

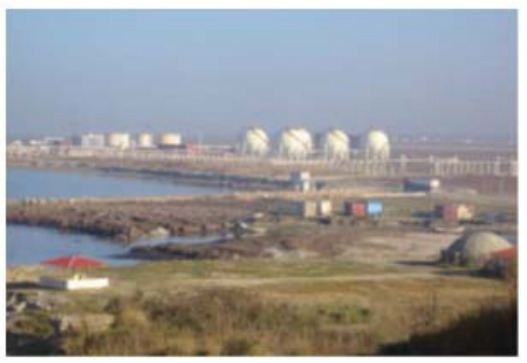

Fig.2. Porto Romano Energy Industrial Zone

\footnotetext{
${ }^{1}$ Adapted from Gwen Swinburn www.worldbank.org

${ }^{2}$ Master of Energy and Industrial Zone of Porto Romano, Durres, V.K.M. Nr. 703, Dt. 23.04.2008 
The land is salty and with a relatively unstable structure which is proved by the previous attempts in the past to use it for agriculture /pasture but which failed. Biodiversity has had great changes because of the continuous interventions and this especially after the drainage of the moor/lagoon. The primeval existence of high mediterrenian coastal vegetation, including oak forests, was replaced after the drainage with garminaceae and other low species, typical of the half desolated wet areas. The biomass in this area is casted as one of the lowest as a result of human interventions or chemical pollutions and its values have decreased double ${ }^{3}$. Since the floods remain the main element risking seriously the investments in this area, which is mainly because of the increase of the level of underground waters, (the ex marshy area has a concave form, where the terrain is lower in its middle), the use of this terrain for this activity is highly observed.

The epicenter of the extension of industrial energetic park is the area of fuel deposits in Porto Romano, opposite which is constructed the pontil (place) for the processing of tank ships transporting oil, gas and its by-products. In spite of having some negative effects from the construction of industrial energetic area in Porto Romano, in relation to habitats, use of land and biodiversity, there are no enviromental impacts, for as long as their value is relatively small from the point of view of natural resources of the area and actual ecological balance. We can also mention that mitigatory measures do not have any considerable cost compared to the investment cost, which give great value to the implementation of this project.

The establishment of this park, will not only stimulate new employement for the local population, but will improve the infrastructure such as energetic network, sanitation and processing of potable water and sewerage avoiding contamination of groundwater and marine area of the bay. These changes, of course taking into account the development plans of all the area and its sorroundings as well as the characteristcs in question, will promote a controlled management of the study area, focused on the industrial and commercial one.

\subsection{The Biopark}

One of the most ambitious projects which gives development alternatives of this rural area interweaved with natural and economic unfavourable areas is the "Bio-Park" campus.

The complex project of "Bio-Park" is included in the category of important projects aiming at the economic growth of the area in question and beyond, through the application of modern technology for the production of alternative, environmentally friendly energy. The strategic objective of the implementation of this project is to improve the social and economic conditions in the rural and unfavourable areas, ensuring at the same time preservation of the environment by avoiding the specific impacts that may be found in the area where is being constructed.

This development model, if applicable expresses its potential in an unfavorable area, without vegetation, with nonproductive land, exposed to erosion and destructive effects of the nature because of appropriate and timely noninterventions with necessary investments. Such development models in unfavorable areas constitute a practice of an accelerated, efficient model of social, economic and environmental development in an area which is economically unactivated because of salty land, presence of almost all year round of seawater and rain water collected mainly during the rainfall.

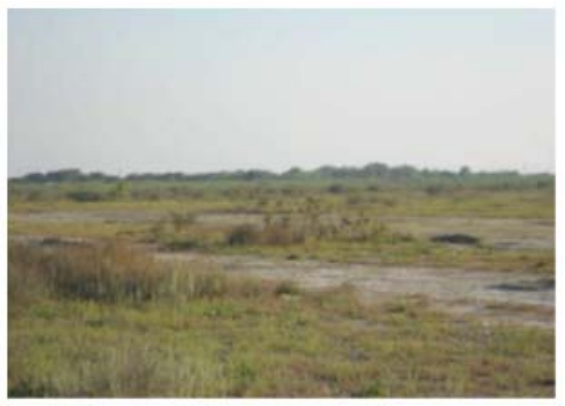

Fig.3. Favored territories ( Bisht Kamez)

\footnotetext{
${ }^{3}$ Bio-Park Project in the area of Bisht-Kamëz. www.scribd.com/doc/72026971
} 
The area where the project is expected to be implemented consists of a wetland territory between the sand strip and the first pine strip along almost the whole coast of the Ishem-Porto Romano coastal area. The surface where this development model will be applied includes a flat, non-productive territory of $382 \mathrm{ha}^{4}$, limited in the North by the estuary of Erzeni river, in the West $150 \mathrm{~m}$ far from the sand strip, in the East from the first strip of pines. The land where the BioPark will be built is not agriculture land and not useful which is mainly used for pasture. The area selected for the implementation of this project is located in Bisht Kamëz near Rinia village, the commune of "Katund i Ri". This area has been selected to be transformed in an intensive, social, economic and evironmental development area. The advantage of this location consists of favorable climate conditions, geographic position and exit in the Adriatic sea.

In economic terms the construction of Bio Park with modern technology will be an important intervention in the market of food and energetic products. This would not only improve the quantity and quality of products but will be coordinated with other activities of economic life of the area.

By implementing this project, there woud be an improvement of the infrastructure, irrational use of the surface to be built, through ecological greenhouses, desalination plant and tubs with solar panels installed in the water surface.

In environmental terms the construction of Bio Park does not have any negative impacts in this area because it is characterized by:

- An area with very poor fauna;

- An area with salty land which is not used for agricultural and farming activity;

- An area with continuous flooding by the rainfalls and sea water;

- An interest-free area for other profitable economic activities;

- An almost uninhabited area;

The construction of this project based on the laws and principles of advanced science and technology, comprises a synchronized system where the interaction between men and environment is in complete harmony.

Indicators of the synchronized interaction of this development model are:

- Desalination of seawater enables the cultivation of marine fish and fresh water;

- Electrical and thermal energy obtained through the use of solar energy.

- Ecological greenhouses;

- Regulator of river outflow;

The solar panels of an advanced technology use the direct sun rays and the distributed ones to turn them into electrical and thermal energy which will provide with energy the campus and the sorrounding community.

The ecological greenhouses about 200 of them, having each a surface of $5000 \mathrm{~m}^{2}$, are completely in harmony with the environment, entirely excluding the pollutants. In these green houses you can grow any safe and health cultural variety starting from medical herbs to trees and fruit trees. The new technology offers high efficiency rates, providing $100 \%$ organic products. ${ }^{5}$ It should be emphasised that in environmental terms the regulator of Erzeni outflow is very important for this project. It will enable the regulation of flows when the river is full of water, the control of quality of urban waste spill. The current situation presents environmental problems in relation to the flooding potential that the river has and urban flow which freely flow at the sea causing pollution which has not only visual consequences but it affects the entire habitat system of different species.

There will be new work places from the construction of Bio-Park such as in aquaculture, ecological greenhhouses and facilities and recreative potentials which will be created in this area, significantly improving the living conditions of the inhabitants.

\subsection{The resort of "Lalzi Bay Resort and SPA".}

Another ambitious project which is applicable in this coastal area situated in rural and unfavourable territories is the Resort of "Lalzi Bay Resort and Spa". This resort is being built near the Gulf of Lalzi in Hamallaj, an area known for its virgin beauty with unspoilt beaches and sand.

\footnotetext{
4 http://www.aic.org.al/wp-content/uploads/2012/10/Bio-parku-dhe-Infrastruktura-e-Bisht-Kamez

${ }^{5}$ http://www.aic.org.al/wp-content/uploads/2012/10/Bio-parku-dhe-Infrastruktura-e-Bisht-Kamez 


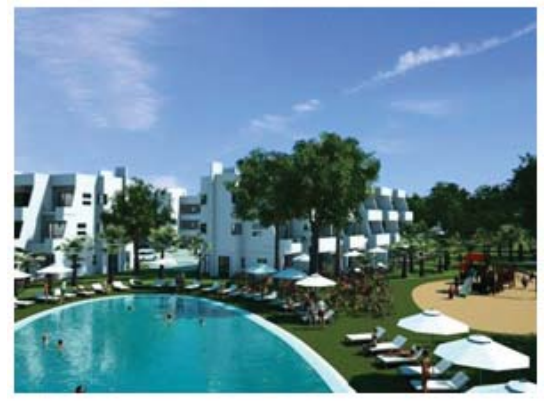

Fig.4. Resort "Lalzi Bay Resort and SPA"

The selected area in addition to natural conditions which it offers for the tourism, it is favored by the geographical position as well. Only thirty minutes from Rinas airport, it offers an attraction of foreign and local tourists. The project started to be implemented in 2011 and is expected to be finished in 20146, in a rural area which in the past was not favored by economic investments. This project under Master Plan for the development of tourism in Lalzi Bay, besides the tourist villages constructed or in the process of construction such as "Lura", "Peshkatari" is a contemporary investment, where the design touches all aspects of a tourist village. The architecture is synchronous with the environment and the surrounding landscape, with low density buildings, gardens, restaurants, swimming pools, playground, etc. This touristic residential campus contains a mixture of villash, flats and shops with a height that does not exceed grass. There will be offered different facilities by the functioning of some distinct areas such as;

Hotel Beach with the Beach Club, swimming pool and functional area;

- Residents beach with cafes and restaurants;

- Public beach with bars and beach carrier, which will have volleyball courts and other different water sports;

These tourist developments convert this rural area in a region with social economic development having development impacts for the surrounding areas. A considerable number of residents will be employed directly or indirectly as the project will enable the development of other economic activities especially agriculture and farming to be provided with their products.

\section{Conclusions}

Despite the efforts during these years to integrate the area in a sustainable development, the concept of rural and unfavorable areas development in Albania remains still a relatively new concept and is not properly included in the local or regional development policies. Nowadays the problem of the villages in this area is employment affecting directly their welfare. With the construction of Industrial Energetic Area of Porto Romano, the construction of touristic villages and resorts in Lalzi Bay, the implementation of BioPark project in Katundi i Ri, we will have a significant quantitative and qualitative improvement both in economy and infrastructure. There will be opportunities for the development of new productive and leisure activities which will have a great social and economic interest and would soften the unemployement wound affecting the emigration as well.

In this context it is the duty of central and local government to finish these projects. The development of the General Local Plan in order to offer an efffective, balancing and integrating solution to different social-economical factors, including the demographic ones, employment, economic growth and prosperity.

\section{Recommendations}

To accelerate the development rate in this area, it is necessary to increase the involvement of local government and stakeholders in planning, directing and managing the development processes in order to ensure a better harmonization of needs, interests and development factors; 
$>$ The increase of productive capacity should be based on the local, economical and social conditions by building over the competitive advantages and existing potentials like clear alternatives of sustainable development;

$>$ Community involvement in development policies as a decision-taking and profitable partnership, commitment to build its local capacity.

$>$ Absorbing the investments, especially in the tourism industry shall be associated with the involvement of different community groups in economic activities and shall be focused on promoting a favorable environment for the economic development of the area and connection to the regional economy;

$>$ Make concrete investments in tourism as the best alternative of sustainable development of the area;

> Investors and donators of these projects should seek from the local and central government to affect with regional financial policies so that this economic orientation can be of interest to more than one administrative unit.

\section{References}

IFAD, 2005, Republic of Albania Programme for sustainable development in Rural Mountain areas. Modern concepts, Economicus Magazine 3. Tirana page.81-91

Marku, Sh. Treska, T. (2009). Development policies of rural and unfavorable areas, need for

MPAU. (2007); Development and Integration National Strategy,

MPSHB, 2007, Social Involvement Strategy 2007-2013

Bio-Park Project in the area of Bisht-Kamëz. Katund i Ri Commune "Durresi District" Report on Environmental Impact Assessment (nontechnical). 2012 http://www.aic.org.al/wp-content/uploads/2012/10/

Non technical report on environmental impact assessment for the construction of the refinery complex in the energetic area of Porto Romano. www.scribd.com/doc/72026971

UNDP.2002. How to make local development work. 